\title{
A INFLUÊNCIA DE RAYMOND WILLIAMS PARA A CONSTRUÇÃO DO CONCEITO DE CULTURA NA CIÊNCIA DA INFORMAÇÃO NO BRASIL
}

\author{
Ísis Trindade da Silva Cunha ${ }^{1}$ \\ Universidade Federal de Pernambuco, UFPE \\ p.acad.it@gmail.com \\ Rafael Silva da Câmara \\ Universidade Federal da Paraíba, UFPB \\ rafaelufrnbib@gmail.com \\ Leilah Santiago Bufrem ${ }^{3}$ \\ Universidade Federal do Paraná, UFPR \\ santiagobufrem@gmail.com
}

\begin{abstract}
Resumo
Análise diacrônica das contribuições históricas expressas nos artigos científicos de pesquisadores bolsistas de produtividade em pesquisa do Conselho Nacional de Desenvolvimento Científico e Tecnológico, para o debate embasado em Raymond Williams no campo da Ciência da Informação, mais especificamente no interdomínio relacionado aos aspectos culturais. Apresenta a concepção adotada como fundamento do estudo, investigando a influência de Williams para as pesquisas sobre cultura na área. Identifica a produção científica dos agentes que constituem o grupo de pesquisadores de produtividade em Ciência da Informação, e que referenciaram Williams. Seleciona os artigos desses autores para verificar os temas presentes nessa produção e os periódicos científicos nos quais são publicados. Analisa essas contribuições, relacionando-as entre si e com as concepções presentes na literatura pertinente. $\mathrm{O}$ estudo permitiu identificar uma pequena parcela das publicações pesquisadas como citante de obras de Williams, porém é possível constatar que mais da metade dos artigos que trazem o autor como referência tratam sobre cultura. A pesquisa também demonstra a inclinação de dois pesquisadores em citar as obras de Raymond Williams, considerando suas publicações correspondem quase a metade do corpus da pesquisa. Foi possível observar que a publicação dos artigos analisados se encontra dispersa entre os diversos periódicos da área.
\end{abstract}

Palavras-chave: Raymond Williams. Cultura. Bolsistas de produtividade do CNPq. Ciência da Informação.

\section{THE INFLUENCE OF RAYMOND WILLIAMS FOR THE CONSTRUCTION OF THE CONCEPT OF CULTURE IN INFORMATION SCIENCE IN BRAZIL}

\begin{abstract}
Diachronic analysis of the historical contributions expressed in scientific articles by research productivity scholars from the National Council for Scientific and Technological Development, for the debate based on Raymond Williams in the field of Information Science, more specifically in the interdomain related to cultural aspects. It presents the conception adopted as the basis of this descriptive and documentary study, investigating the influence of Williams for research on culture in the area. It identifies the scientific production in Information Science, of the agents that constitute the group of productivity researchers and that referenced Williams. It selects the articles of these authors to verify the themes present in this production and the scientific journals. It analyzes these contributions, relating them to each other and to the concepts present in the relevant literature. The study allowed to identify a small portion of the publications researched as citing Williams' works, however it is possible to verify that more than half of the articles that bring the author as a reference deal with culture. The research also

\footnotetext{
${ }^{1}$ Possui graduação em Jornalismo pela Faculdade Maurício de Nassau - Recife (2009).

${ }^{2}$ Doutor em Ciência da Informação pelo Programa de Pós-graduação em Ciência da Informação da Universidade Federal da Paraíba (PPGCI UFPB).

${ }^{3}$ Doutorado em Ciências da Comunicação pela Universidade de São Paulo, Brasil (1991)

Pesquisadora 1D do Conselho Nacional de Desenvolvimento Científico e Tecnológico, Brasil.
} 
demonstrates the inclination of researchers Marco Almeida and Leilah Bufrem to cite the works of Raymond Williams, since their publications correspond to almost half of the research corpus. It was possible to observe that the publication of the analyzed articles is dispersed among different journals.

Keywords: Raymond Williams. Culture. CNPq productivity fellows. Information Science

\section{INTRODUÇÃO}

A forte ligação existente entre a Ciência da Informação (CI) e a Cultura tem sido concretizada ao longo do surgimento e evolução de ambas e ocorre devido ao objeto de estudo da informação estar fortemente interligado com a segunda, uma vez que a cultura se utiliza da informação para fluir, permanecer e expandir-se ao longo do tempo e comunicar-se com outras áreas. Analogamente, a informação não ocorre fora da cultura, conforme percepção decisiva para este estudo, pelo qual se procura compreender a construção de um conceito de cultura, concretizado a partir dos estudos culturais. Enquanto percebe a cultura como campo de luta, esse movimento a compreende a partir de sua conexão com as relações sociais e de poder, reunindo a um só tempo análises literárias e sociopolíticas. Um dos pensadores decisivos desse movimento para a compreensão da cultura, Raymond Williams representa essa forma de discutir os fatos da cultura, reunindo a um só tempo análises literárias e sociopolíticas.

Natural do País de Gales, Raymond Williams, era filho de pais ferroviários assentados em área rural. Logo cedo teve contato com o movimento operário e partidos do campo progressista. Williams viveu períodos entre guerras, assistiu o enfraquecimento da economia local, migrações e desempregos. Aos 11 anos ganhou uma bolsa de estudos para a escola King Henry VIII Grammmar School, em Abergavenny, aos 14 anos iniciou a militância política vinculando-se ao Partido Comunista da Grã-Bretanha e ao Partido Trabalhista Britânico (o Labour). Integrou o movimento chamado Nova Esquerda (New Left), formado por membros insatisfeitos com o proceder do Partido Trabalhista. Aos 18 anos, graças ao desempenho escolar destacado, ingressou no Trinity College, em Cambridge, onde cursou letras em inglês e se dedicou a política estudantil. Em 1947 lançou a revista Politics and Letters, seu primeiro projeto de intervenção cultural, com a colaboração de dois colegas de Cambridge, cuja vida foi curta, mas de atuação marcante para um momento de crise na vida de Williams (Cevasco, 2001). Williams dedicou-se aos estudos acerca do significado do termo cultura e sua relação com a sociedade, empregando seus esforços junto a um grupo de pensadores marxistas do pós-guerra, contra o elitismo de direita e o dogmatismo da esquerda. "Uma das principais críticas que esse grupo de intelectuais de esquerda fazia em relação à visão tradicional de cultura era que, 
centrada na educação ou nas artes, reproduzia a desigualdade social mesmo se colocando como 'herança da humanidade' ou o 'repositório dos valores espirituais'” (TAVARES, 2008, p. 9).

Com a propagação do pensamento dos Estudos Culturais, na década de 1960, Williams passou a ministrar aulas nas universidades em Cambridge e em Stanford University. Aposentou-se em 1983, passando a se dedicar à escrita de obras ficcionais.

O objetivo geral deste estudo é demonstrar a receptividade do pensamento de Williams entre os bolsistas de produtividade em pesquisa do Conselho Nacional de Desenvolvimento Científico e Tecnológico (CNPq) em CI. Pretende-se, especificamente: a) identificar a produção científica sobre cultura dos pesquisadores do $\mathrm{CNPq}$ da $\mathrm{CI}$; b) analisar o universo temático representado pelas palavras-chave dos artigos citantes de Williams; c) identificar as fontes dos artigos citantes; d) analisar diacronicamente a produção sobre cultura dos pesquisadores $\mathrm{CNPq}$ da CI.

\section{POR UMA CONCEPÇÃO DE CULTURA PARA O ESTUDO}

Os estudos etimológicos de Williams exploram o sentido do termo, a partir de sua origem e a apropriação de significados no decorrer dos séculos. Originado do latim: colere, para significar habitar (daí colono, colônia), adorar, cuidar (daí o culto religioso ou cultivo da terra) passou a ser usado, no século XVI, como cultivo do espírito e das faculdades mentais. A partir do século XVIII, associado à palavra civilização (civitas: ordenado, educado), o termo passou a se relacionar a um progresso intelectual e espiritual, individual ou coletivo. A ideia estava ligada ao desenvolvimento da civilização europeia, em contraposição ao barbarismo, conforme o ideário francês. Já os alemães, associaram a ideia de cultura (Kultur) com os valores subjetivos e relativos (questões do espírito) e a civilização ao uso da razão e dos valores universais. Como argumenta Eagleton (2005, p. 45), a cultura significava, então

[...] essa esplêndida síntese. Era o abrigo precário onde podiam se refugiar os valores e as energias para os quais o capitalismo não tinha nenhum uso. Era o lugar onde o erótico e o simbólico, o ético e o mitológico, o sensorial e o emocional podiam fazer sua morada dentro de uma ordem social que dispunha de cada vez menos tempo para qualquer um deles.

Acompanhando o pensamento de Williams sobre a cultura, Cevasco (1999, p. 76) parte da trajetória pessoal do autor, para quem "estudar a cultura pode ser a porta de entrada para uma crítica empenhada, que visa entender o funcionamento da sociedade com o objetivo de transformá-la”. A posição teórica do materialismo cultural adotada por Williams justifica a centralidade da cultura como uma categoria teórica predominante para as vertentes da crítica 
materialista, articulando a produção cultural às condições materiais da sociedade Seus estudos articulam-se na direção de um projeto intelectual cujas principais questões representam a "crise da cultura contemporânea”, especialmente graças à polêmica instaurada em setores dos estudos culturais.

Em "Cultura e sociedade", Williams (1969) analisa o conceito de cultura, presente em textos significativos (teóricos, críticos e literários) escritos entre 1780 e 1950. Afirma que "o conceito de cultura e a própria palavra, em seus usos gerais modernos, surgiram no pensamento inglês, no período comumente chamado da Revolução Industrial” (WILLIAMS, 1969, p. 11).

Diante de um conceito tão amplo, que traz consigo importantes significações para diversas áreas do conhecimento, surge a necessidade de investigar sua relação com a Ciência da Informação, a fim de entender as colaborações trazidas por ele à área, por meio da sua relação com a informação, termo tão abrangente e polissêmico quanto o primeiro.

Em recente estudo sobre a prática da pesquisa em relação aos quadros teóricos concorrentes no campo de produção científica em CI, Bufrem (2017) reconhece a sua aproximação com as correntes teóricas positivistas e as chamadas pós-modernas do século XIX e XX, cujo arquétipo filosófico e epistemológico gerou um expressivo espectro de aplicabilidades, para uso das ciências, de um modo geral. Neste estudo, os modelos mais representativos foram o positivista, o estruturalista e o pós-modernista, presentes nos discursos acadêmicos dos pesquisadores da elite da área de CI, recebendo atenção, especialmente nos interdomínios do campo da produção científica relacionados à cultura. Compondo um corpus integrado pelos fundamentos teóricos do campo de produção científica em análise, o conhecimento registrado de diversas áreas, como a sociologia, a filosofia, a linguística, a antropologia, a psicologia, a estatística, a economia e a matemática, permite o crescimento e as transformações dos domínios pelos quais transitam os produtores do conhecimento (BUFREM, 2017).

No texto Cultura da modernidade: discussões e práticas informacionais, de autoria de Marteleto (1994), tem- se um panorama do fenômeno informacional ao perpassar contextos e processos para se constituir objeto de estudo da Ciência da Informação, usando como conceito norteador a cultura, termo que segundo a autora "fornece solo teórico a partir do qual novos conceitos se delineiam. " (MARTELETO, 1994). A produção interpreta a informação como um artifício norteador das interações sociais e da relação com a realidade, um elemento de acesso aos signos e significados. A cultura, por sua vez seria o produto das interações sociais sustentadas pelo uso da informação. O texto, não só encontra pontos de intersecção entre cultura e informação, como demonstra entender essa relação como uma relação antropológica. 
De forma diferente, a informação, desde a sua elaboração como objeto científico, possui um componente técnico, que mais tarde irá cada vez mais se aproximar da noção de cultura como bem simbólico, integrado ao fluxo de trocas da sociedade. É este o momento de aproximação entre cultura e informação. (MARTELETO, 1994).

A passagem reafirma a necessidade de explorar a relação entre os campos cultura e ciência da informação, demonstrando a ocorrência de interseção entre eles. A informação carrega consigo um contexto proveniente de seus interlocutores e do contexto social, político e econômico em que surgiu, o que faz com que adquira um teor cultural.

Essas relações evidenciadas são objeto de reflexão de Martins e Marteleto (2019, p. 22). Apoiadas em Gramsci, elas consideram que o elo indissociável entre cultura-ideologiahegemonia permite:

a) pensar os objetos informacionais a partir das lógicas organizativas da produção hegemônica das sociedades capitalistas, cuja base de reprodução é material e ideológica; b) vislumbrar, a partir das formas dos dispositivos informacionais, em sua relação dialética com o conteúdo, mediações do processo de organização global da hegemonia econômica e política; c) apreender, nos cenários de práticas informacionais e comunicacionais que se disseminam, as determinações ideológicas vinculadas à esfera da recriação contínua das fronteiras do sistema capitalista, com vistas à sua expansão; d) situar a informação nos confrontos simbólicos pela direção moral e intelectual, na instituição de quadros de significados particulares que se apresentam como universais e que atuam na produção e reprodução da vida e da realidade simbólica-material; e) perceber o papel organizativo dos intelectuais, sua vinculação com a construção do nacional popular e, ao mesmo tempo, a falência dessa função em uma sociedade que vai ocultando as "mediações"; f) compreender as organizações da sociedade civil como espaços de produção de contra hegemonias, mas também de consensos a partir da produção e circulação da informação.

Essa contribuição favorece a crítica ao cenário político atual, onde o poder do capital tem naturalizado formas inconcebíveis de existência, que acabam sendo aceitas como inevitáveis, quando, de fato, elas são resultantes das forças do mercado, com visível desiquilíbrio social.

A inspiração no roteiro de Williams motivou este estudo por uma análise da evolução do conceito de cultura na produção científica de pesquisadores brasileiros, relacionando-o aos temas, periódicos e influências teóricas representadas por autores considerados seminais. A percepção da polêmica contra alguns setores dos estudos culturais acríticos deixa claro o ponto nevrálgico representado pela posição de Williams, ao relacionar a história da ideia de cultura com a história dos modos de reagir intelectual e emocionalmente à mudança de condições por que passou a nossa vida. Assim, o autor compreende a cultura como

[...] a nossa resposta aos acontecimentos que constituem o que viemos a definir como indústria e democracia e que determinaram a mudança das condições humanas. [...] A ideia de cultura é a resposta global que demos à grande mudança geral que ocorreu nas condições de nossa vida comum. (WILLIAMS, 1969, p. 305). 
Williams (1992) enfatiza a dificuldade do termo cultura e destaca alguns aspectos da história e uso do termo o qual passou por significativas transformações (p. 10-12). Ele defende uma forma de "convergência contemporânea" que "encara a cultura como o sistema de significações mediante o qual necessariamente (se bem que entre outros meios) uma dada ordem social é comunicada, reproduzida, vivenciada e estudada" (p. 13).

[...] há certa convergência prática entre (i) os sentidos antropológico e sociológico de cultura 'como modo de vida global' distinto, dentro do qual percebe-se, hoje, um 'sistema de significações' bem definido não só como essencial, mas como essencialmente envolvido em todas as formas de atividade social, e (ii) o sentido mais especializado, ainda que também mais comum, de cultura como 'atividades artísticas e intelectuais', embora estas, devido à ênfase em um sistema de significações geral, sejam agora definidas de maneira muito mais ampla, de modo a incluir não apenas as artes e as formas de produção intelectual tradicionais, mas também todas as 'práticas significativas' - desde a linguagem, passando pelas artes e filosofia, até o jornalismo, moda e publicidade - que agora constituem esse campo complexo e necessariamente extenso (WILLIAMS, 1992. Grifos do autor).

Haveria convergência, atualmente? Ou com a influência da pós-modernidade o conceito se dilui cada vez mais? Sobre a cultura popular:

[...] a dinâmica real do processo sociocultural é mais notória nas transformações do 'popular', que caminharam não só ao longo de uma trajetória que vai das formas anteriores de cultura 'folclórica' até as novas formas parcialmente auto-organizadas de cultura popular urbana, mas ainda ao longo de uma trajetória de extensa - e maciçamente - produção de cultura 'popular' pelo mercado burguês e pelos sistemas educacional e político estatais. (WILIAMS, 1992, p. 226).

Sob esta perspectiva, de democratização de acesso a todos os indivíduos aos bens culturais da humanidade e, mais especificamente, aos conhecimentos ou saberes historicamente produzidos, procurou-se apresentar como a teoria de Williams vem sendo apropriada no campo da CI como fundamento de sua prática.

\section{TRAJETÓRIA METODOLÓGICA}

Com a finalidade de atender os objetivos pretendidos foram seguidas as seguintes etapas nesta pesquisa descritiva e documental: a) identificação da produção científica dos bolsistas CNPq na área da CI relacionada à temática cultura e citante de Williams; b) processamento e padronização dos dados coletados em planilhas eletrônicas e matrizes; c) observações diacrónicas sobre estas produções científicas; d) identificação das fontes dos artigos e pesquisadores PQ em CI citantes de Williams; e e) elaboração de gráficos, grafo, quadros e nuvem de palavras-chave para visualização e análise nos softwares Microsoft Excel, Ucinet, Netdraw e portal eletrônico Wordclouds. 


\section{INFLUÊNCIA DE WILLIAMS PARA A CONSTRUÇÃO DO CONCEITO DE CULTURA NA CIÊNCIA DA INFORMAÇÃO}

O grupo de pesquisa "Educação, Pesquisa e Produção Científica", cadastrado no Diretório dos Grupos de Pesquisa do CNPq mantem um projeto de construção de uma base de dados em constante organização e atualização, que registra as publicações em periódicos científicos da CI realizadas por pesquisadores agraciados com bolsas de produtividade em pesquisa do CNPq. Por meio desta fonte, foram levantadas as publicações científicas com a terminologia “cultura" nos campos referentes ao Título, às Palavras-chaves e ao Resumo, bem como levantadas as publicações científicas com referências a Williams no campo destinado ao registro das Referências.

Na terminologia "cultura" foram identificadas 197 publicações e quanto à referência a Williams foram identificadas 17 publicações, sendo que destas últimas, nove publicações também são sobre cultura. No gráfico 1 é apresentada a linha temporal destas produções levantadas, categorizando quanto ao tema "Cultura" e a referência a Williams.

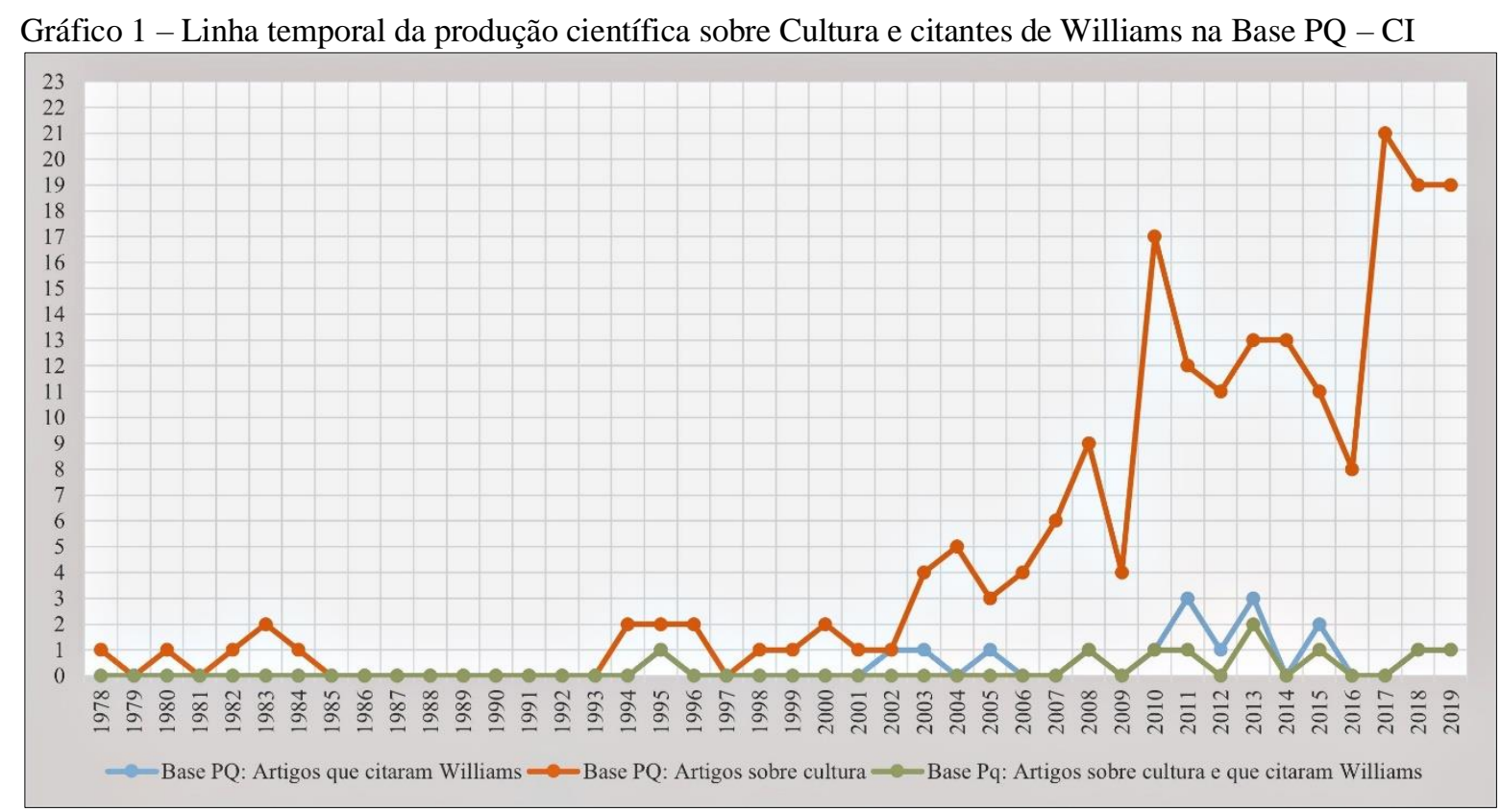

Fonte: Elaboração própria (2020)

A primeira fase de produções sobre cultura na linha temporal é visualizada entre os anos de 1978 e 1994. Esta fase com poucas publicações se segue até o ano de 2001. Entretanto, a primeira publicação nesta área temática e que referencia Williams é identificada em meados da 
última década do século XX, quando Targino (1995) reforça que toda a obra do filósofo é voltada para as relações entre cultura, tecnologia e sociedade. Já no começo do século XXI é percebido um aumento desta produção científica, sendo possível dividir esta elevação em três períodos de seis anos cada.

Para este novo recorte referente ao aumento da produção científica, o primeiro período do novo século compreende os anos entre 2002 e 2007 . Aqui, a primeira publicação identificada e que referencia Williams é a de Pereira e Bufrem (2002) que apresentam uma proposta de prática de ensino-aprendizagem com pesquisa em fontes de informação especializadas, consubstanciada no "Projeto Produção de Instrumentos Bibliográficos", sendo esta iniciativa apoiada em pressupostos de Williams.

Tavares e Freire (2003) referenciaram Williams para tratar da transformação cultural como um processo lento, mas necessário na sociedade para as mudanças de atitude em relação ao tratamento de resíduos sólidos, sendo estes decorrentes de problemas culturais.

Aspectos linguísticos da representação do conhecimento foram estudados por Bufrem, Silva e Breda (2005), que elucidaram Williams e as teorias do Círculo de Bakhtin, assumindo a linguagem como consciência prática em todas as atividades sociais e produtivas.

O segundo período compreende os anos entre 2008 e 2013. Almeida (2008) inseriu Williams ao lado de outros pensadores como Antônio Gramsci, Richard Hoggart e Edward Thompson como autores seminais que contribuem para os fundamentos teóricos, temáticos e metodológicos para os estudos culturais em mediação da informação, particularmente no Grupo de Trabalho (GT) "Mediação, circulação e uso da informação", nomenclatura do GT na época, da Associação Nacional de Pesquisa e Pós-Graduação em Ciência da Informação (Ancib). Já Targino (2010) inseriu Williams ao lado de teóricos como Manuel Castells, Michael Schudson e Alvin Toffler para evidenciar a inter-relação entre sociedade e tecnologia, uma vez que as revoluções tecnológicas caminham, simultaneamente, com a história. Para essa ênfase na tecnologia, contribuiu a crítica de Williams ao determinismo tecnológico, cujos seguidores identificam a tecnologia como o próprio motor da história ou causa última das transformações sociais, assim como seu olhar crítico à sociologia da tecnologia de natureza funcionalista, segundo a qual as transformações tecnológicas resultam de necessidades sociais, como uma resposta que a própria sociedade, mais cedo ou mais tarde, produz, no sentido de satisfazê-las.

A produção científica dos que referenciaram Williams teve mais um pequeno aumento no ano de 2011 com as publicações de Bufrem e Gabriel Júnior (2011), que problematizaram as noções de conceito na CI e as relações com o processo histórico; de Crippa e Almeida (2011), que discutiram a natureza e aspectos informacionais da mediação artística e patrimonial no 
espaço urbano; e de Biscalchin e Almeida (2011) que propuseram uma revisão do conceito de autoria e aspectos legais do direito autoral na internet, refletindo as posições das publicações em CI em relação aos novos paradigmas provocados pela tecnologia.

Ao analisar as diferentes representações da ciência construídas no processo de divulgação científica, Orrico (2012) pautou-se em Williams para tratar da história do conceito de representação e o uso político da construção do significado.

Encerrando este segundo período de produções que referenciaram Williams, são identificadas as publicações de Gehrke e Bufrem (2013), que se remeteram às discussões de Williams sobre engajamento e luta, para caracterizarem os sujeitos da escola do campo no estado do Paraná e as práticas de uso nas bibliotecas escolares, expressando a relação entre a cultura da biblioteca escolar e a Escola do Campo; de Silva e Albagli (2012), que utilizaram do conceito de cultura desenvolvido por Williams para análises sobre a arte e a linguagem como principais elementos das estratégias informacionais e comunicacionais do movimento hip hop; e de Schneider (2013), que cotejou as noções de cultura dominante, emergente e residual, de Williams, com as reflexões de Gramsci sobre extratos mais retrógrados ou progressistas da cultura popular, para contextualizar a crítica da economia política dos estudos culturais.

No terceiro e último período da linha temporal, entre os anos de 2014 e 2019, Schneider (2015) trouxe uma nota de Williams a respeito da ideia de gosto não poder ser separada da ideia de consumidor, novamente utilizando como recurso à crítica da economia política. Ainda no mesmo ano, Silva e Morigi (2015) propuseram um fluxo transmidiático configurado no percurso do receptor entre as diferentes mídias, a partir das contribuições de Williams, Klaus Bruhn Jensen e Elisa Reinhardt Piedras. Lara e Mendes (2018) apresentaram o conceito de cultura em Williams para trazerem a importância das reflexões de Suzanne Briet no que tange às relações entre a técnica cultural e o perfil do profissional de documentação. E por fim, Almeida (2019) coloca a obra "Bibliografia e Sociologia dos Textos", de Donald Francia Mckenzie, em releitura dialogada com outros autores que refletem os processos tecnoculturais, onde se inclui Williams.

Os canais de comunicação científica selecionados pelos autores que referenciaram Williams se mostram bastante diversificados, conforme a figura 1 que apresenta a distribuição dos periódicos científicos entre os pesquisadores bolsistas PQs em CI. 
Figura 1 - Grafo de periódicos das publicações científicas dos PQs que referenciaram Williams

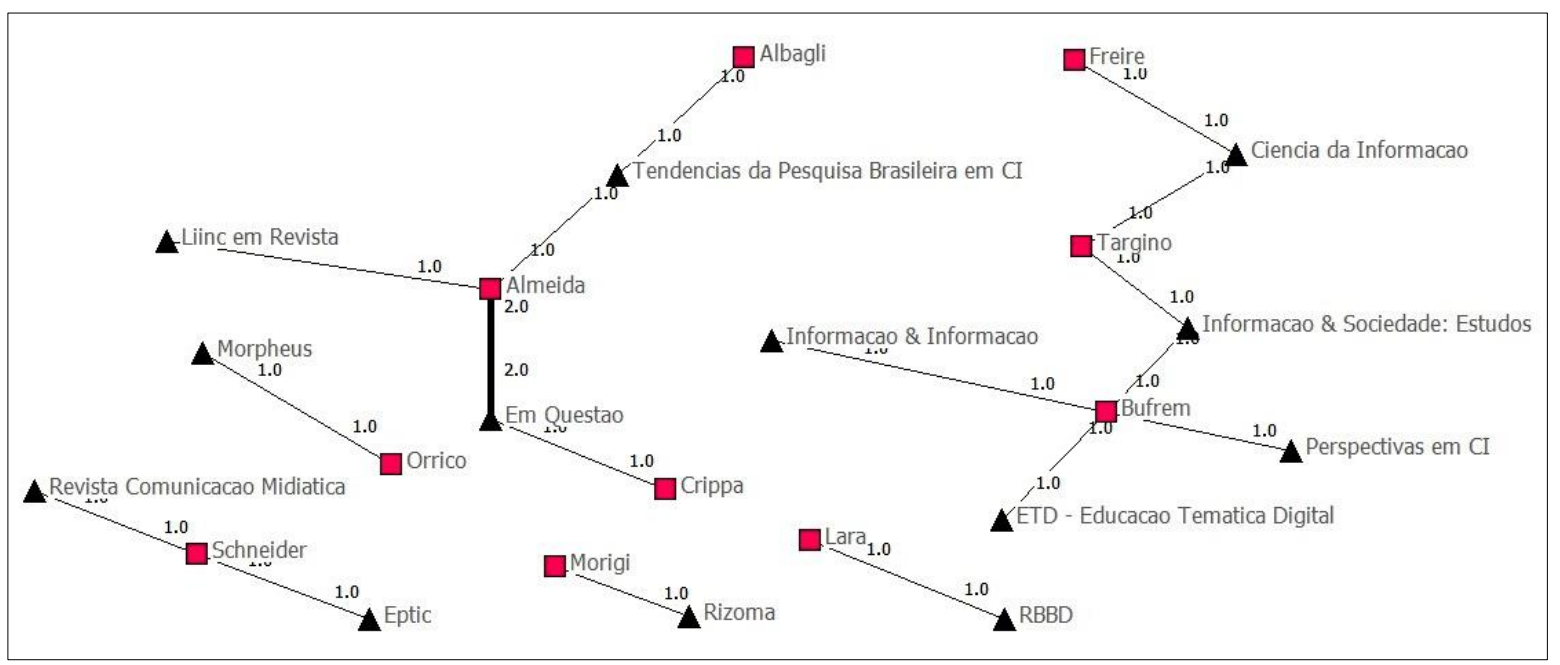

Fonte: Elaboração própria (2020)

Para fins de identificação e reconhecimento, são percebidos dez autores ao todo como pesquisadores que foram ou que ainda são enquadrados como PQ nos níveis 1 e 2 pela concessão de bolsa de produtividade em pesquisa do CNPq e que citaram Williams em suas produções: Marilda Lopes Ginez de Lara, Sarita Albagli, Leilah Santiago Bufrem, Giulia Crippa, Isa Maria Freire, Evelyn Goyannes Dill Orrico, Marco André Feldman Schneider, Valdir José Morigi, Marco Antônio de Almeida e Maria das Graças Targino.

As obras de Williams foram registradas conforme as ocorrências de referências apresentadas nas publicações dos PQs e apresentadas no Quadro 1.

Quadro 1 - Ocorrências de obras de Williams referenciadas pelos PQs em CI

\begin{tabular}{|c|c|}
\hline PQs & Ocorrências de obras de Williams referenciadas \\
\hline BUFREM & $\begin{array}{l}\text { 1. WILLIAMS, R. O campo e a cidade na história e na literatura. São Paulo: } \\
\text { Companhia das Letras, } 2011 . \\
\text { 2. WILLIAMS, R. Culture and society. London: Lawrence and Wishart, } 1977 . \\
\text { 3. WILLIAMS, R. Marxism and literature. Oxford: Oxford University Press, } \\
\text { 1977. } \\
\text { 4. WILLIAMS, R. The long revolution. London: Chatto \& Windus, } 1961 . \\
\text { 5. WILLIAMS, R. O campo e a cidade na história e na literatura. São Paulo: } \\
\text { Companhia das Letras, } 1989 . \\
\text { 6. WILLIAMS, R. Cultura. Rio de Janeiro: Paz e Terra, } 2008 . \\
\text { 7. WILLIAMS, R. Palavras-chave: um vocabulário de cultura e sociedade. São } \\
\text { Paulo: Boitempo, } 2007 .\end{array}$ \\
\hline ALBAGLI & 1. WILLIAMS, R. The Long Revolution. London, UK: Chatto and Windus, 1961. \\
\hline CRIPPA & tura. Rio de Janeiro: Paz e Terra, 2000. \\
\hline
\end{tabular}




\begin{tabular}{|c|c|}
\hline ALMEIDA & $\begin{array}{l}\text { 1. WILLIAMS, R. Cultura. Rio de Janeiro: Paz e Terra, } 2000 . \\
\text { 2. WILLIAMS, R. Cultura. Rio de Janeiro, Paz e Terra, } 1992 . \\
\text { 3. WILLIAMS, R. Palavras-chave: um vocabulário de cultura e sociedade. São } \\
\text { Paulo: Boitempo, } 2007 . \\
\text { 4. WILLIAMS, R. Marxismo e literatura. Rio de Janeiro: Zahar, } 1979 . \\
\text { 5. WILLIAMS, R. Cultura. Rio de Janeiro: Paz e Terra, } 1992 . \\
\text { 6. WILLIAMS, R. Cultura. Rio de Janeiro: Paz e Terra, } 1992 .\end{array}$ \\
\hline FREIRE & 1. WILLIAMS, R. Cultura. Rio de Janeiro: Paz e Terra, 1992 \\
\hline LARA & 1. WILLIAMS, R. Cultura. 2. ed. Rio de Janeiro: Paz e Terra, 2000. \\
\hline ORRICO & $\begin{array}{l}\text { 1. WILLIAMS, R. Palavras-chave: um vocabulário de cultura e sociedade. Trad. } \\
\text { Sandra Guardini T. Vasconcelos. São Paulo:, Boitempo, } 2007 .\end{array}$ \\
\hline SCHNEIDER & $\begin{array}{l}\text { 1. WILLIAMS, R. Key words. New York: Oxford University Press, } 1985 . \\
\text { 2. WILLIAMS, R. Base and superestructure in marxist cultural theory. New Left } \\
\text { Review, London, v. 1. n. 82, p. 3-16, nov./dec. } 1973 . \\
\text { 3. WILLIAMS, R. Cultura. São Paulo: Paz e Terra, } 2000 . \\
\text { 4. WILLIAMS, R. Marxismo e literatura. Rio de Janeiro: Zahar, } 1979 .\end{array}$ \\
\hline MORIGI & $\begin{array}{l}\text { 1. WILLIAMS, R. Television: Technology and cultural form. London: Routledge } \\
\text { 2.ed. } 1990 .\end{array}$ \\
\hline TARGINO & $\begin{array}{l}\text { 1. WILLIAMS, R. Culture and society. London: Penguin, 1985. 347p. } \\
\text { 2. WILLIAMS, R. The politics of modernism; against the new conformists. } \\
\text { London: Verso, 1989. 208p. Culture and technology, p.119-139. } \\
\text { 3. WILLIAMS, R. Cultura. São Paulo: Paz e Terra, 1992. 239p. } \\
\text { 4. WILLIAMS, R. Culture and society. London: Penguin, 1992. } \\
\text { 5. WILLIAMS, R. Culture and technology. In: WILLIAMS, R. The politics of } \\
\text { modernism: Against the new conformists. London: Verso, 1989. p.119-139. }\end{array}$ \\
\hline
\end{tabular}

Fonte: Elaboração própria (2020)

Mesmo com variações entre os pesquisadores em relação aos objetos e objetivos de pesquisa, este quadro permite observar certa afinidade quanto à escolha das obras referenciadas, independente das características da referência como ano de publicação, local, língua estrangeira ou portuguesa. Obras como "Cultura", "Cultura e Sociedade", "Palavras-chave" e "Marxismo e Literatura" foram referenciadas por mais de um PQ, inferindo assim relações de acoplamento bibliográfico entre as publicações científicas do corpus de pesquisa.

As produções científicas destes pesquisadores também foram analisadas quanto às suas palavras-chave, evidenciando o universo temático do que foi observado nas análises diacrônicas. Para tanto, duas nuvens de palavras-chave foram criadas, sendo a primeira representativa da produção dos PQs citantes de Williams. Já a segunda nuvem é um recorte da primeira, pois além de estarem ligadas às publicações citantes de Williams, se enquadram na produção científica sobre cultura. 
Figura 2 - Nuvem de palavras-chave nas publicações científicas dos que referenciaram Williams e na produção sobre Cultura

\begin{tabular}{|c|c|}
\hline 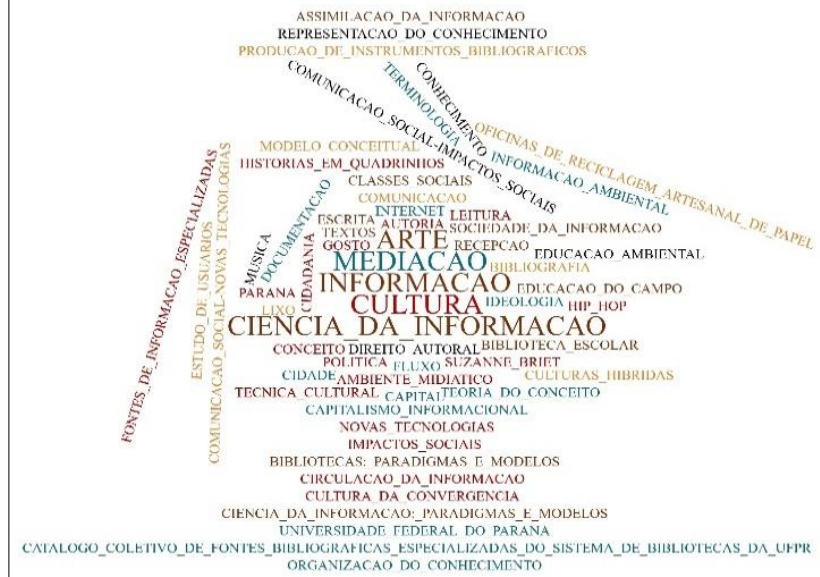 & 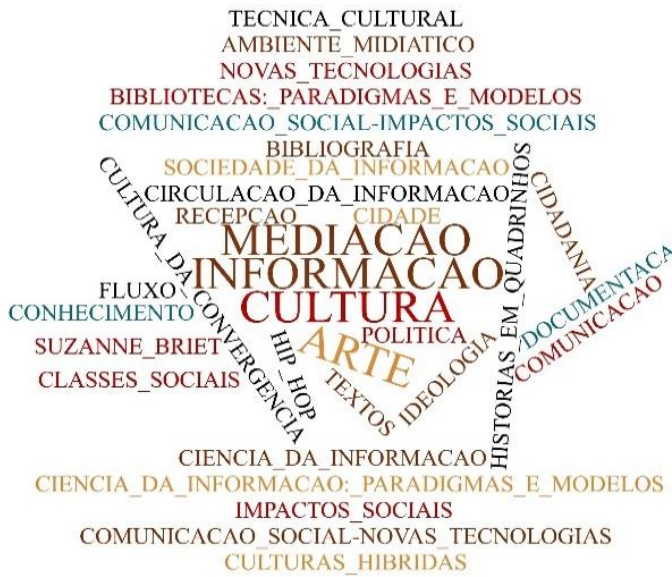 \\
\hline
\end{tabular}

Fonte: Elaboração própria (2020)

Representativas dos artigos, 60 palavras-chave foram identificadas, das quais 32 também estão relacionadas às produções sobre cultura. As palavras-chave "informação" e "cultura" permanecem em destaque centralizadas em ambas as nuvens de palavras devido a intersecção existente entre os dois campos do conhecimento, áreas exploradas por esta pesquisa.

Fica evidente também o destaque para os temas "mediação" e "arte". A palavra-chave "mediação" ganha contornos com pesquisas que fomentaram discussões acerca do papel da mediação da informação e cultura, assim como, do mediador na sociedade contemporânea, considerando as especificidades dos grupos que a compõem. Essa relação é fortalecida pelo ao grupo de trabalho "Mediação, circulação e uso da informação" da ANCIB, cujas reflexões sobre os conceitos de mediação e mediador, definem demarcações conceituais nas ciências sociais. $\mathrm{O}$ papel do mediador é discutido prioritariamente a partir de uma perspectiva política e cultural da atividade mediadora. Destacam-se, nesse contexto a aproximação com as posições de Gramsci acerca das noções de cultura e hegemonia e sua incorporação pela corrente dos estudos culturais ingleses. A palavra-chave "arte" também se destaca no centro da nuvem e contribui para o debate sobre as manifestações culturais na construção do repertório e identidade cultural dos grupos sociais.

\section{CONSIDERAÇÕES FINAIS}

É válido salientar que as temáticas apreciadas observadas na produção citante de Williams sobre cultura encontram em sua obra substancial fundamentação teórica, uma vez que o autor considera que o estudo da cultura é o caminho para a compreensão do funcionamento da 
sociedade, meio pelo qual será possível alterá-la. Ao verificar que, embora seja uma pequena parcela dos artigos sobre cultura que citam Williams, pouco mais da metade da produção que o referencia apresenta a temática cultura. Essa constatação sugere a importância do autor e de sua obra na construção de um conceito de cultura, principalmente quando as discussões sobre a temática apresentam debates nas relações de poder e na sociedade capazes de garantir ou usurpar o direito de todos à informação e a cultura.

O estudo de Raymond Williams sobre o conceito de cultura é vasto e consistente e permitiu aos pesquisadores fundamentar uma grande variedade de temáticas ligadas à cultura. Debates como a relação entre cultura tecnologia e sociedade, os estudos culturais em mediação da informação, a mediação artística e patrimonial no espaço urbano, a relação entre cultura e biblioteca escolar, a economia política, o fluxo transmidiático e os processos tecnoculturais, foram alguns dos temas dos quais os bolsistas encontraram na obra de Williams subsídios para desenvolver.

Em resposta ao objetivo de pesquisa, a demonstração da influência de Williams entre os bolsistas PQs em CI, é possível inferir a aproximação teórica não apenas quanto ao autor, mas também quanto as suas obras em comum referenciadas pelos PQs. Em relação à produção científica sobre cultura, sugere-se a perspectiva de investigação sobre outros autores influentes ao lado de Williams nas pesquisas já desenvolvidas.

As análises geradas nestes estudos demonstram a importância de investigar as relações interdominiais que cercam a Ciência da Informação, com o propósito de compreender o intercambio conceitual de cultura com outras áreas do conhecimento. 


\section{REFERÊNCIAS}

ALMEIDA, M. A. Mediações da cultura e da informação: perspectivas sociais, políticas e epistemológicas. Tendências da Pesquisa Brasileira em Ciência da Informação, v. 1, n. 1, 2008. Disponível em: http://hdl.handle.net/20.500.11959/brapci/119328. Acesso em: 24 jan. 2021.

ALMEIDA, M. A. O frasco quebrado: a bibliografia e a cultura da convergência. Em Questão, Porto Alegre, v. 25, p. 243-263, 2019. DOI: http://dx.doi.org/10.19132/18085245250.243-263. Disponível em: https://seer.ufrgs.br/EmQuestao/article/view/92325. Acesso em: 24 jan. 2021.

BISCALCHIN, A. C. S.; ALMEIDA, M. A. Direitos autorais, informação e tecnologia: impasses e potencialidades. Liinc em Revista, Rio de Janeiro, v. 7, n. 2, p. 638-652, set. 2011. DOI: https://doi.org/10.18617/liinc.v7i2.424. Disponível em: http://revista.ibict.br/liinc/article/view/3310. Acesso em: 24 jan. 2021.

BUFREM, L. S.; SILVA, H. F. N.; BREDA, S. M. Contribuições teóricas para uma revisão dos princípios e práticas da representação do conhecimento. ETD - Educação Temática Digital, Campinas, v. 7, n. 1, p. 28-38, dez. 2005. DOI: 10.20396/etd.v7i1.593. Disponível em: https://periodicos.sbu.unicamp.br/ojs/index.php/etd/article/view/593. Acesso em: 24 jan. 2021.

BUFREM, L.S. A prática da pesquisa e os quadros teóricos concorrentes no campo de produção científica em ciência da informação. P2P \& Inovação, v.4, n. 1, set./fev. 2018.

BUFREM, L.S.; GABRIEL JÚNIOR, R. F. A apropriação do conceito como objeto na literatura periódica científica em Ciência da Informação. Inf. Inf., Londrina, v. 16, n. 3, p. 5291, jan./jun. 2011. DOI: http://dx.doi.org/10.5433/1981-8920.2011v16n2p52. Disponível em: http://www.uel.br/revistas/uel/index.php/informacao/article/view/10387. Acesso em 24 jan. 2021.

CEVASCO, M. E. B. P. S. Dez lições sobre estudos culturais. 2 ed. São Paulo: Boitempo, 2008.

CEVASCO, M. E. B. P. S. Prefácio. In: Palavras-chave: um vocabulário de cultura e sociedade. São Paulo: Boitempo, 2007, p. 10-20.

CEVASCO, M. E. B. P. S. Para ler Raymond Williams. São Paulo: Paz e Terra, 2001.

CEVASCO, M. E. B. P. S. Para ler Raymond Williams. 1999. 211 f. Trabalho apresentado para concurso (Livre-docência). Faculdade de Filosofia, Letras e Ciências Humanas, Departamento de Letras Modernas, Universidade de São Paulo, 1999.

CRIPPA, G.; ALMEIDA, M. A. Mediações artísticas e informacionais no contexto urbano: algumas reflexões e paradoxos. Em Questão, Porto Alegre, v. 17, n. 1, p. 127-142, jan./jun. 2011. Disponível em: https://seer.ufrgs.br/EmQuestao/article/view/18852. Acesso em: 24 jan. 2021.

EAGLETON, T. A idéia de cultura. São Paulo: Unesp, 2005. 
GEHRKE, M.; BUFREM, L. S. Apontamentos sobre bibliotecas em escolas do campo no estado do Paraná. Inf. \& Soc.: Est., João Pessoa, v. 23, n. 3, p. 109-122, set./dez. 2013. Disponível em: https://periodicos.ufpb.br/ojs/index.php/ies/article/view/16673. Acesso em: 24 jan. 2021.

LARA, M. L. G.; MENDES, L. C. Suzanne Briet e a documentação como técnica cultural. Revista Brasileira de Biblioteconomia e Documentação, São Paulo, v. 14, p. 75-89, jul. 2018. Disponível em: https://rbbd.febab.org.br/rbbd/article/view/1179. Acesso em: 24 jan. 2021.

MARTELETO, R. M. Cultura da Modernidade: discussões e práticas informacionais. Revista da Escola de Biblioteconomia da UFMG, v. 23, n. 2, 1994.

MARTELETO, R. M.; MARTINS, A. A. L. Cultura, ideologia e hegemonia: Antonio Gramsci e o campo dos estudos da informação. INCID - Revista de Ciência da Informação e Documentação, v. 10, n. 1, mar./ago. 2019.

ORRICO, E. A memória da divulgação científica: um discurso informacional. Morpheus, Rio de Janeiro, v. 9, n. 14, p. 114-130, 2012. Disponível em: Acesso em: 24 jan. 2021.

PEREIRA, E. C.; BUFREM, L. S. Fontes de informação especializada: uma prática de ensino-aprendizagem com pesquisa na Universidade Federal do Paraná. Perspect. Cienc. Inf., Belo Horizonte, v. 7, n. 2, p. 197-206, jul./dez. 2002. Disponível em: http://portaldeperiodicos.eci.ufmg.br/index.php/pci/article/view/408. Acesso em: 24 jan. 2021.

SCHNEIDER, M. Os sentidos da música, o dinheiro e a mídia. Rev. Comun. Midiática, Bauru, v. 9, n. 3, p. 25-40, set./dez. 2014. Disponível em: https://www2.faac.unesp.br/comunicacaomidiatica/index.php/CM/article/view/170. Acesso em: 24 jan. 2021.

SCHNEIDER, M. Comunicação, classes sociais e cidadania: crítica da economia política dos estudos culturais. Revista Eptic Online, v. 15, n. 3, p. 4-18, set./dez. 2013. Disponível em: https://seer.ufs.br/index.php/eptic/article/view/1352. Acesso em: 24 jan. 2021.

SILVA, K. V.; SILVA, M. H. Dicionário de conceitos históricos. 2. ed. São Paulo: Contexto, 2006.

SILVA, N. S. S.; MORIGI, V. J. Fluxo Transmidiático: entre as possibilidades de discutir a recepção no ambiente de mídias. Rizoma, Santa Cruz do Sul, v.3, n. 1, p. 81-93, jul. 2015. DOI: http://dx.doi.org/10.17058/rzm.v3i1.5330. Disponível em: https://online.unisc.br/seer/index.php/rizoma/article/view/5330. Acesso em: 24 jan. 2021.

SILVA, R.; ALBAGLI, S. Arte, informação e conhecimento na cultura Hip Hop. Tendências da Pesquisa Brasileira em Ciência da Informação, v. 5, n. 1, 2012.

TARGINO, M. G. A biblioteca do século xxi: novos paradigmas ou meras expectativas? Inf. \& Soc.: Est., João Pessoa, v. 20, n. 1, p. 39-48, jan./abr. 2010. Disponível em: https://periodicos.ufpb.br/ojs/index.php/ies/article/view/2645. Acesso em: 24 jan. 2021. 
TARGINO, M. G. Novas tecnologias de comunicação: mitos, ritos ou ditos? Ci. Inf., Brasília, v. 24, n. 2, 1995. Disponível em: http://revista.ibict.br/ciinf/article/view/586. Acesso em: 24 jan. 2021.

TAVARES, Hugo Moura. Raymond Williams: pensador da cultura. Revista Ágora, Vitória, n. 8, 2008, p.1-27. Disponível em: Acesso em: 24 jan. 2021.

TAVARES, C.; FREIRE, I. M. "Lugar do lixo é no lixo": estudo de assimilação da informação. Ci. Inf., Brasília, v. 32, n. 2, p. 125-135, maio/ago. 2003. Disponível em: http://revista.ibict.br/ciinf/article/view/1012. Acesso em: 24 jan. 2021.

WILLIAMS, R. Palavras-chave: um vocabulário de cultura e sociedade. São Paulo: Boitempo, 2007.

WILliAMS, R. Cultura. Rio de Janeiro: Paz e Terra, 1992.

WILLIAMS, R. Cultura e sociedade. São Paulo: Editora Nacional, 1969. 